\title{
Aplicação de coagulante natural no abrandamento de água calcária do Aquífero Bambuí, Norte de Minas Gerais, Brasil
}

\author{
Natural coagulant application for softening hard water of the Bambuí Aquifer, \\ north of Minas Gerais state, Brazil
}

\author{
Gustavo Lopes Muniz $\left.{ }^{1}{ }^{*}\right)$ \\ Francinete Veloso Duarte ${ }^{2}$ \\ Suelaine Barbosa de Oliveira ${ }^{3}$
}

\section{Resumo}

Na região Norte do estado de Minas Gerais, as águas subterrâneas do aquífero Bambuí caracterizam-se como águas duras por apresentar elevadas concentrações de carbonato de cálcio, o que tem provocado entupimentos nos sistemas de abastecimento e de irrigação. A Moringa oleifera tem sido mundialmente estudada por ser uma alternativa viável para o tratamento de água. Objetivou-se, neste estudo, analisar o efeito de diferentes dosagens da semente da moringa e diferentes tempos de sedimentação na remoção da dureza total e na variação da alcalinidade e do pH de água subterrânea do Aquífero Bambuí, norte de Minas Gerais. O experimento foi conduzido em delineamento inteiramente ao acaso, com três repetições, em esquema fatorial $3 \times 3 \times 2$ (três dosagens de sementes de moringa, três tempos de sedimentação e dois tipos de sementes), mais a testemunha. Os resultados mostraram que o efeito da interação dosagem*tipo de semente*tempo de sedimentação é significativo na redução da dureza, sendo que esta diminuiu consideravelmente com relação ao tratamento testemunha. A alcalinidade também reduziu com o aumento da dosagem de moringa e do tempo de sedimentação. $\mathrm{O}$ pH oscilou entre 7,55 e 8,27; o que contribuiu para a precipitação de carbonato, pois foi suficiente para aumentar o índice de saturação da água.

Palavras-chave: Água subterrânea; dureza, Moringa oleifera; tratamento de água.

1 Me.; Engenharia Agrícola; Universidade Federal de Viçosa, UFV, Brasil; Doutorando no programa de Pós-Graduação em Engenharia Agrícola na FEAGRI - UNICAMP, na área de concentração em Água e Solo; Endereço: Universidade Estadual de Campinas, Faculdade de Engenharia Agrícola. Avenida Cândido Rondon, Cidade Universitária. CEP: 13083875 - Campinas, SP - Brasil; E-mail: gustavolopesmuniz@yahoo.com.br

2 Me.; Engenharia Metalúrgica e de Minas; Professora EBTT (Ensino Básico Técnico e Tecnolópgico) da Universidade Federal de Minas Gerais; Universidade Federal de Minas Gerais, Instituto de Ciências Agrárias. Avenida Universitária, 1000. CEP: 39404006 - Montes Claros, MG - Brasil; E-mail: francinete@ica.ufmg.br

3 Graduada; Química; Técnica em laboratório / área química da Universidade Federal de Minas Gerais; Endereço Profissional - Universidade Federal de Minas Gerais, Instituto de Ciências Exatas. Avenida Universitária, Universitário. CEP: 39404547 - Montes Claros, MG - Brasil; E-mail: suelaine.barbosa@yahoo.com.br

\begin{tabular}{llllll}
\hline Ambiência & Guarapuava (PR) & v.14 n.2 & p. 252-266 & Maio/Ago 2018 & ISSN $1808-0251$
\end{tabular}




\section{Abstract}

In the northern region of Minas Gerais State, Brazil, groundwater of the Bambuí Aquifer are characterized as hard water by containing high calcium carbonate concentration, which has caused blockages in water supply and irrigation systems. Moringa oleifera has been studied worldwide because it is viable alternative for the hard water treatment. This study aimed to analyze the effect of different doses of Moringa oleifera seed and different sedimentation times in removing total hardness and in variation of alkalinity and $\mathrm{pH}$ of groundwater of the Bambuí Aquifer, north of Minas Gerais state. The experiment was carried out in a completely randomized design with three replicates in $3 \times 3 \times 2$ (three doses of moringa oleifera seeds, three sedimentation times, and two types of seeds) factorial scheme and the witness treatment. Results showed that the interaction effect dose*seed type*sedimentation time is significant for reducing the water hardness with considerable positive effect compared to the witness treatment. Alkalinity also was reduced by increasing the amount of moringa dosage and sedimentation time. The $\mathrm{pH}$ ranged between 7,55 and 8,27, which contributes to carbonate precipitation, because it was enough to increase the water saturation index.

Key words: ground water, toughness, Moringa oleifera, water treatment

\section{Introdução}

Com o acelerado crescimento populacional, a utilização de água subterrânea tem sido alternativa atraente para o abastecimento doméstico e industrial, por ser de boa qualidade natural e se encontrar mais protegida das áreas em processos de degradação (CORDEIRO et al., 2012).

As águas subterrâneas em contato com rochas calcárias caracterizam-se por apresentar altas concentrações de íons $\mathrm{Ca}^{+2}$ e $\mathrm{Mg}^{+2}$, já que a água está intimamente em contato com materiais solúveis do solo e das rochas, apresentando assim, elevado teor de dureza (GHIZELLAOUI et al., 2005; CORDEIRO et al., 2012).

A água dura provoca uma série de problemas em instalações hidráulicas domésticas e industriais devido à precipitação do carbonato de cálcio, o que leva ao entupimento e deterioração dessas instalações (OUYANG et al., 2008). Além disso, águas com elevado teor de dureza proporcionam aumento no consumo de detergente, sabonete, shampoo, produtos de limpeza e até mesmo de energia (ANDREASEN; STUBSGAARD, 2002). Em sistemas de irrigação, essas águas levam ao rápido entupimento dos gotejadores, sendo, portanto, impróprias para a irrigação localizada (DUARTE, 2010).

A precipitação química tem sido frequentemente utilizada para abrandamento de água (BRASTAD; HE, 2013). Esse procedimento caracteriza-se por acrescentar cal à água dura para precipitar íons de cálcio na forma de carbonato de cálcio e íons de magnésio na forma de hidróxido de magnésio (BRUGGEN; VANDECASTEELE, 2003). No entanto, esse procedimento tem como desvantagem a produção de elevado volume de lodo e a necessidade de correção do $\mathrm{pH}$ da água após o abrandamento (BRASTAD; HE, 2013).

Outros métodos de abrandamento de água reportados na literatura incluem: troca iônica, osmose reversa, eletrodiálise, nanofiltração e nanotubos de carbono, que, por sua vez, têm como desvantagem a adição de produtos químicos à água, exigem alto gasto de energia, possuem 
custo operacional elevado e geram problema ambiental com os efluentes salinos obtidos nesses processos de abrandamento (SEO et al.,2010; TOFIGHY; MOHAMMADI, 2011; BRASTAD; HE, 2013; CUDA; POSPISIL, 2006). Assim sendo, é necessário a busca por procedimentos ambientalmente sustentáveis, de baixo custo e eficientes para o abrandamento de águas calcárias.

A região Norte de Minas Gerais, geologicamente, apresenta afloramentos de gnaisses arqueanos, pertencentes ao embasamento cristalino, rochas carbonáticas e terrígenas que compõem o Grupo Bambuí, arenitos do Grupo Urucuia (Cretáceo) e coberturas recentes (SOUZA et al., 2014). Ainda de acordo com Souza et al. (2014), em função da presença de rochas calcárias, o aquífero Bambuí pode ser dividido, em: fraturado, fraturado-cárstico e cárstico, sendo que, de forma geral, as áreas de maior produtividade dos poços correspondem às áreas cársticas, em que predominam rochas calcárias.

As águas subterrâneas do Aquífero Bambuí são consideradas águas duras, apresentando valores de dureza que variam de 150 a mais de 1261 ppm em $\mathrm{CaCO}_{3}$, exclusivamente devido a íons cálcio e magnésio (DUARTE, 2010, SOUZA et al., 2014).

A moringa (Moringa oleifera Lam.) é uma planta pertencente à família Moringaceae, composta apenas de um gênero (Moringa) e quatorze espécies conhecidas, nativa do Norte da Índia, desenvolve-se atualmente em vários países dos trópicos (BEZERRA et al., 2004; SILVA et al., 2011). Ainda de acordo com esses mesmos autores, essa planta é facilmente propagada por adaptar-se a uma ampla faixa de solo e ser tolerante à seca.

$\mathrm{O}$ uso das sementes de moringa no tratamento de água constitui uma alternativa de baixo custo em relação ao tratamento químico convencional (PATERNIANI et al. 2009) e, ainda, as sementes de moringa apresentam vantagem de não causarem problemas de corrosão e não alterarem, significativamente, o pH e a alcalinidade da água (GALLÃO et al., 2006).

Muyibi e Evison (1995) utilizaram sementes de moringa com as cascas para o abrandamento de águas de quatro fontes diferentes (água sintética - água destilada com adição de $\mathrm{CaCl}$, água superficial de natureza calcária e água subterrânea de dois poços tubulares de diferentes aquíferos do Nordeste da Inglaterra) e observaram que, para a água sintética com valores de dureza iniciais de 300 e $500 \mathrm{mg} \mathrm{L}^{-1}$ em $\mathrm{CaCO}_{3}$, dosagem de $950 \mathrm{mg} \mathrm{L}^{-1}$ de moringa é suficiente para reduzir a dureza da água a zero. Já para as amostras de água real (superficial e água subterrânea), a dosagem máxima estudada pelos autores, de $2400 \mathrm{mg} \mathrm{L}^{-1}$, proporcionou remoção da dureza da água de 1017,1 mg L-1 para 280,0 mg L-1 em $\mathrm{CaCO}_{3}$, 494,5 $\mathrm{mg} \mathrm{L}^{-1}$ para 215,2 $\mathrm{mg} \mathrm{L}^{-1} \mathrm{em} \mathrm{CaCO}_{3}$ e de 496,5 $\mathrm{mg} \mathrm{L}^{-1}$ para 232,2 $\mathrm{mg} \mathrm{L}^{-1} \mathrm{em} \mathrm{CaCO}_{3}$ para as águas superficial e duas amostras de água subterrânea, respectivamente.

Para efeito do coagulante extraído da semente da Moringa oleifera, devem-se retirar as cascas das sementes (NDABIGENGESERE et al., 1995; NDABIGENGESERE \& NARASIAH 1998; PATERNIANI et al., 2009). No entanto, conforme Muniz et al. (2015), o descascamento torna o procedimento complicado e dificultoso para aplicação em larga escala, inviabilizando o uso das sementes da moringa no tratamento de água. Assim, deve-se buscar uma forma de aplicação que torne seu uso mais simples e prático, levando em consideração que não seja necessária a remoção das cascas das sementes para que estas possam ser utilizadas no abrandamento de água.

Desse modo, a presente pesquisa buscou avaliar o efeito da presença ou ausência da casca da moringa na eficiência do processo de abrandamento de águas calcárias, bem como, avaliar o uso da moringa como coagulante para abrandamento das mesmas. 


\section{Material e métodos}

\section{Aparato experimental}

O experimento foi conduzido no Laboratório de Química Analítica do Instituto de Ciências Agrárias da Universidade Federal de Minas Gerais (UFMG) em Montes Claros - MG.

As sementes da moringa utilizadas no preparo da solução coagulante foram coletadas em árvores situadas no Instituto de Ciências Agrárias. Assim que coletadas, parte das sementes tiveram suas cascas removidas e outra parte permaneceu com as cascas.

As amostras de água duras utilizadas no experimento foram provenientes do poço tubular localizado no Instituto de Ciências Agrárias da UFMG em Montes Claros - MG, que faz parte do aquífero Bambuí. A coleta da água foi feita diretamente da saída da bomba sem passar pelo reservatório.

\section{Procedimento experimental}

A remoção das sementes da vagem e das cascas foi feita manualmente. Ambas as sementes foram trituradas em liquidificador doméstico, seguindo recomendações de Ndabigengesere et al., (1995) e Katayon et al. (2006), e peneiradas para a padronização de tamanho (PATERNIANI et al., 2009; PATERNIANI et al., 2010).

A solução coagulante foi preparada e utilizada no mesmo dia seguindo recomendações de Ndabigengesere e Narasiah (1998).

Foram pesadas em uma balança analítica 250,500 e $1000 \mathrm{mg}$ de pó de sementes de moringa, trituradas com casca e sem casca, cujas quantidades foram adicionadas em $1 \mathrm{~L}$ de água do poço. Após a adição do pó de sementes de moringa, os tratamentos foram levados para o agitador magnético a $1300 \mathrm{rpm}$, durante $20 \mathrm{~min}$, para os ensaios de coagulação.

Após a coagulação, os tratamentos foram mantidos em repouso por 1,6 e $15 \mathrm{~h}$ para a sedimentação. Passado o tempo de sedimentação, a amostra foi filtrada com papel filtro (NDABIGENGESERE; NARASIAH, 1998; OKUDA et al., 2001; KATAYON et al., 2006) e imediatamente analisadas de acordo com o Standard Methods for the examination of water and wastewater (APHA, 2005).

\section{Delineamento estatístico}

Utilizou-se o delineamento inteiramente casualizado em esquema fatorial $(3 \times 3 \times 2)+1$ com três repetições dos tratamentos, pelo qual foram estudados três níveis de dosagem de sementes de moringa (250, 500 e $\left.1000 \mathrm{mg} \mathrm{L}^{-1}\right)$, três tempos de sedimentação (1, 6 e $15 \mathrm{~h}$ ) e dois tipos de sementes (com casca e sem casca), mais a testemunha.

\section{Variáveis analisadas e tratamento estatístico}

Foram analisadas a dureza total, $\mathrm{Ca}^{+2}, \mathrm{Mg}^{+2}$, alcalinidade e $\mathrm{pH}$. Todas as variáveis foram determinadas antes e após o procedimento de coagulação/floculação, obtendo, desse modo, a testemunha.

Os dados de dureza total foram submetidos à análise de variância a 1 e $5 \%$ de probabilidade, quando constatada interação significativa entre os fatores, procedeu-se com o desdobramento dos graus de liberdade e as médias foram comparadas pelo teste de Tukey a 5\% de significância. Para 
comparação com a testemunha, utilizou-se o teste de Dunnet a 5\% de probabilidade. As médias de variação da alcalinidade, $\mathrm{pH}, \mathrm{Ca}^{+2} \mathrm{e} \mathrm{Mg}^{+2}$ foram descritas em gráficos confeccionados no Excel. As análises foram realizadas utilizando o pacote estatístico Sistema de Análise de Variância para Dados Balanceados - SISVAR (FERREIRA, 2000).

\section{Resultados e discussão}

A interação dupla dosagem*tempo de sedimentação e a interação tripla dosagem*tipo de semente*tempo de sedimentação foram significativas a 1 e $5 \%$ de probabilidade, respectivamente, (Tabela 1) indicando existir dependência entre os efeitos desses fatores no abrandamento de água calcária.

\section{Tabela 1 - Resultado da análise de variância para a dureza total}

\begin{tabular}{ccc}
\hline Fontes de variação & GL & Fc \\
\hline Dosagem & 2 & $212,25^{* *}$ \\
Tipo de semente & 1 & $7997,02^{* *}$ \\
Tempo de sedimentação & 2 & $1536,66^{* *}$ \\
Dosagem*Tipo de semente & 2 & $1,31^{\mathrm{ns}}$ \\
Dosagem*Tempo de sedimentação & 4 & $5,61^{* *}$ \\
Tipo de semente*Tempo de sedimentação & 2 & $0,31^{\mathrm{ns}}$ \\
Dosagem*Tipo de semente*Tempo de sedimentação & 4 & $2,69^{*}$ \\
Tratamentos*Testemunha & 1 & $4701,67^{* *}$ \\
Resíduo & 38 & \\
Total & 56 & \\
CV (\%) & & 0,28 \\
\hline
\end{tabular}

Fonte: Muniz, G. L. et al. (2018)

Nota: $G L=$ Graus de liberdade; $F C=F$ calculado; ** significativo em nível de $1 \%$ de probabilidade; *significativo em nivel de $5 \%$ de probabilidade; $n s$ = não significativo; $C V$ = coeficiente de variação.

Todos os tratamentos diferiram da testemunha $(\mathrm{p}<0.01)$, que apresentou dureza inicial de 237,0 $\mathrm{mg} \mathrm{L}^{-1} \mathrm{em} \mathrm{CaCO}_{3}$. Assim, verifica-se que os fatores estudados influenciam diretamente o abrandamento de água.

$\mathrm{Na}$ Tabela 2 encontra-se o desdobramento da interação dosagem*tempo de sedimentação.

\section{Tabela 2 - Médias de dureza final $\left(\mathrm{mg} \mathrm{L}^{-1}\right)$ para a interação dosagem*tempo de sedimentação}

\begin{tabular}{cccc}
\hline \multirow{2}{*}{ Dosagem $\left(\mathbf{m g ~ L}^{-\mathbf{1}}\right)$} & $\mathbf{1}$ & Tempo de sedimentação (h) \\
& $202,37 \mathrm{aA}$ & $\mathbf{6}$ & $\mathbf{1 5}$ \\
\hline 250 & $198,13 \mathrm{bA}$ & $190,27 \mathrm{aB}$ & $189,60, \mathrm{aC}$ \\
500 & $193,53 \mathrm{cA}$ & $188,50 \mathrm{cB}$ & $186,80 \mathrm{bC}$ \\
1000 & & $181,23 \mathrm{cC}$ \\
\hline
\end{tabular}

DMS (Tukey 5\%) para colunas $=1,57 \quad$ DMS (Tukey $5 \%$ ) para linhas $=1,57$

Fonte: Muniz, G. L. et al. (2018)

Nota: Para cada linha, médias de tempo de sedimentação seguidas de letra maiúscula diferentes diferem entre si, a $5 \%$ de probabilidade pelo teste de Tukey. Para cada coluna, médias de dosagem seguidas de letras minúsculas 
A dureza da água diminuiu gradativamente à medida que se aumentou a dosagem de moringa e o tempo de sedimentação, sendo a dureza residual observada de $181,2 \mathrm{mg} \mathrm{L}^{-1} \mathrm{em}$ $\mathrm{CaCO}_{3}$ com $1000 \mathrm{mg} \mathrm{L}^{-1}$ de sementes de moringa e $15 \mathrm{~h}$ de sedimentação. Para todas as dosagens, o melhor tempo de sedimentação foi o de $15 \mathrm{~h}$, que proporcionou maior remoção da dureza total. Para todos os tempos de sedimentação estudados, a melhor dosagem foi $1000 \mathrm{mg} \mathrm{L}^{-1}$ de extrato de sementes, onde foram observados menores valores de dureza residual.

Observações semelhantes foram feitas quando se realizou o desdobramento da interação tripla, oportunidade em que foi estudado o comportamento dos níveis de dosagem, do tempo de sedimentação e do tipo de semente dentro de cada nível dos respectivos fatores. Os resultados são mostrados nas Tabelas 3 e 4.

\section{Tabela 3 - Médias de dureza final obtidas do desdobramento dos níveis de dosagens dentro da combinação tempo de sedimentação mais tipo de semente e vice-versa}

\begin{tabular}{ccccccc} 
& \multicolumn{4}{c}{ Sementes sem casca } & \multicolumn{5}{c}{ Sementes com casca } \\
\cline { 2 - 7 } & \multicolumn{6}{c}{ Tempo de sedimentação (h) } \\
\hline $\left.\begin{array}{c}\text { Dosagem } \\
(\mathbf{m g ~ L}\end{array}\right)$ & 1 & $\mathbf{6}$ & $\mathbf{1 5}$ & $\mathbf{1}$ & $\mathbf{6}$ & $\mathbf{1 5}$ \\
\hline 250 & $188,40 \mathrm{aD}$ & $181,47 \mathrm{aE}$ & $176,60 \mathrm{aF}$ & $216,33 \mathrm{aA}$ & $207,07 \mathrm{aB}$ & $202,60 \mathrm{aC}$ \\
500 & $186,07 \mathrm{bD}$ & $176,13 \mathrm{bE}$ & $172,53 \mathrm{bF}$ & $211,20 \mathrm{bA}$ & $204,60 \mathrm{bB}$ & $201,07 \mathrm{aC}$ \\
1000 & $179,47 \mathrm{cD}$ & $174,73 \mathrm{bE}$ & $168,27 \mathrm{cF}$ & $207,60 \mathrm{cA}$ & $202,27 \mathrm{cB}$ & $194,20 \mathrm{bC}$ \\
\hline
\end{tabular}

DMS (Tukey 5\%) para colunas = 0,0777 DMS (Tukey 5\%) para colunas $=0,0956$

Fonte: Muniz, G. L. et al. (2018)

Nota: Médias seguidas pela mesma letra, minúscula nas colunas e maiúsculas nas linhas, não diferem entre si pelo teste de Tukey a $5 \%$ de probabilidade.

Como é observado na Tabela 3, em todas as dosagens estudadas, as sementes utilizadas sem a casca contribuíram de forma mais eficiente na remoção da dureza da água, com o tempo de $15 \mathrm{~h}$ de sedimentação. Ressalta-se que a dosagem de $1000 \mathrm{mg} \mathrm{L} \mathrm{L}^{-1}$ foi a que proporcionou maior remoção, diferindo estatisticamente das demais dosagens, ao nível de 5\% de significância.

As sementes utilizadas com a casca não tiveram a mesma eficiência que as utilizadas sem a casca. Observa-se, na Tabela 4, que as sementes sem casca diferiram estatisticamente das utilizadas com a casca, sendo aquelas mais eficientes que estas. Essa observação é válida para todas as combinações de dosagem com tempo de sedimentação.

Segundo Muyibi e Evison (1995), o mecanismo para a remoção da dureza utilizando as sementes de moringa é a adsorção. As propriedades coagulantes das sementes de moringa são atribuídas a uma série de proteínas catiônicas de baixo peso molecular (MUYIBI; EVISON, 1995) e com alta carga positiva (GASSENSCHMIDT et al., 1995).

Para Ndabigengesere et al. (1995) o agente coagulante é uma proteína dimérica com peso molecular de $13 \mathrm{kDa}$, com subunidades de $6,5 \mathrm{kDa}$ ligadas por ponte dissulfeto, que é solúvel em água, sendo que esta proteína está presente na polpa da semente. Assim sendo, quando utilizadas 
as sementes sem as cascas, a concentração dessas proteínas no extrato coagulante tende a ser maior, o que explica a maior eficiência do extrato de sementes sem casca na remoção da dureza.

\section{Tabela 4 - Médias de dureza final obtidas do desdobramento dos dois tipos de sementes dentro da combinação dosagem mais tempo de sedimentação e vice-versa}

\begin{tabular}{cccc}
\hline $\begin{array}{c}\text { Dosagem } \\
\left(\mathbf{m g ~ L}^{-\mathbf{1}}\right)\end{array}$ & $\begin{array}{c}\text { Tempo de } \\
\text { sedimentação }(\mathbf{h})\end{array}$ & Sementes sem casca & Sementes com casca \\
\hline \multirow{2}{*}{250} & 1 & $188,40 \mathrm{aB}$ & $216,33 \mathrm{aA}$ \\
& 6 & $181,47 \mathrm{cB}$ & $207,07 \mathrm{cA}$ \\
& 15 & $176,60 \mathrm{~dB}$ & $202,60 \mathrm{deA}$ \\
500 & 1 & $185,07 \mathrm{bB}$ & $211,20 \mathrm{bA}$ \\
& 6 & $176,13 \mathrm{~dB}$ & $204,60 \mathrm{cdA}$ \\
1000 & 15 & $172,53 \mathrm{eB}$ & $201,07 \mathrm{eA}$ \\
& 1 & $179,47 \mathrm{cB}$ & $207,60 \mathrm{cA}$ \\
& 15 & $174,73 \mathrm{deB}$ & $202,27 \mathrm{deA}$ \\
& $168,27 \mathrm{fB}$ & $194,20 \mathrm{fA}$ \\
\hline
\end{tabular}

DMS (Tukey 5\%) para colunas $=0,1047 \quad$ DMS (Tukey 5\%) para colunas $=0,0646$

Fonte: Muniz, G. L. et al. (2018)

Nota: Médias seguidas pela mesma letra, minúscula nas colunas e maiúsculas nas linhas, não diferem entre si pelo teste de Tukey a $5 \%$ de probabilidade.

Muyibi e Evison (1995) aplicaram sementes de moringa sem casca no abrandamento de águas de poços subterrâneos, cuja dureza inicial era 495,0 mg L-1 em CaCO${ }_{3}$. Com $1 \mathrm{~h} \mathrm{de}$ sedimentação, e observaram que, com dosagem de $500 \mathrm{mg} \mathrm{L}^{-1}$ de moringa, a dureza da água reduz para 381,0 $\mathrm{mg} \mathrm{L}^{-1} \mathrm{em} \mathrm{CaCO}_{3}$, já com dosagem de $1000 \mathrm{mg} \mathrm{L}^{-1}$ a dureza residual é de apenas $116,0 \mathrm{mg} \mathrm{L}^{-1} \mathrm{em} \mathrm{CaCO}_{3}$. Os resultados encontrados neste trabalho estão em conformidade com Muyibi e Evison (1995), assim como, estão em conformidade com Mangale et al. (2012), segundo os quais, à medida que a dureza da água aumenta, a dose necessária da semente de moringa também aumenta.

Muyibi e Okuofu (1995) estudaram o abrandamento de amostras de água de poços subterrâneos e, também, observaram que a dureza diminui com o aumento da dosagem de moringa. Também foi observado pelos mesmos autores que, para a mesma dureza inicial, amostras de água que contêm dureza de cálcio e magnésio requerem doses mais elevadas de moringa do que as amostras que contêm apenas dureza de cálcio.

Em termos práticos, para abastecimento humano, a portaria 2914 de 2011 do Ministério da Saúde (BRASIL, 2011) estabelece que o limite máximo de dureza na água para consumo humano deve ser de 500,0 $\mathrm{mg} \mathrm{L}^{-1} \mathrm{em} \mathrm{CaCO}_{3}$. Embora a dureza inicial da água estudada esteja dentro dos padrões estabelecidos em Brasil (2011), ressalta-se que, quanto menor for a dureza da água, menor é a probabilidade de ocorrência de incrustações em tubulações e equipamentos. Assim, é desejável que se remova a maior quantidade possível da dureza de modo a evitar a precipitação do $\mathrm{CaCO}_{3}$.

Em relação ao entupimento dos sistemas de irrigação, Pitts et al. (1990) classificam a água como de baixo risco de entupimento quando a dureza é menor que 150,0 $\mathrm{mg} \mathrm{L}^{-1} \mathrm{em} \mathrm{CaCO}_{3}$, 
médio para valores maiores que 150,0 e menores que 300,0 e alto para valores acima de 300,0 ppm. Desse modo, observa-se que, mesmo após o tratamento, a água continua apresentando médio risco de obstrução de gotejadores, entretanto, em função da diminuição das concentrações de $\mathrm{Ca}^{+2}$ e de $\mathrm{Mg}^{+2}$, minimiza-se o risco de obstrução.

A concentração residual de cálcio, variou em função do tempo de sedimentação e da dosagem de moringa aplicada. Na Figura 1, nota-se que o tempo de sedimentação de $15 \mathrm{~h}$ com $1000 \mathrm{mg} \mathrm{L}^{-1}$ de moringa proporcionaram maior remoção do cálcio. Observa-se também que, os tratamentos nos quais foram utilizados extrato de sementes com cascas (Figura 1B) foram menos eficientes na remoção do cálcio.

\section{Figura 1 - Concentração residual de $\mathrm{Ca}^{+2}$ na água em função dos tempos de sedimentação e das dosagens de sementes de moringa sem casca (A) e com casca (B)}
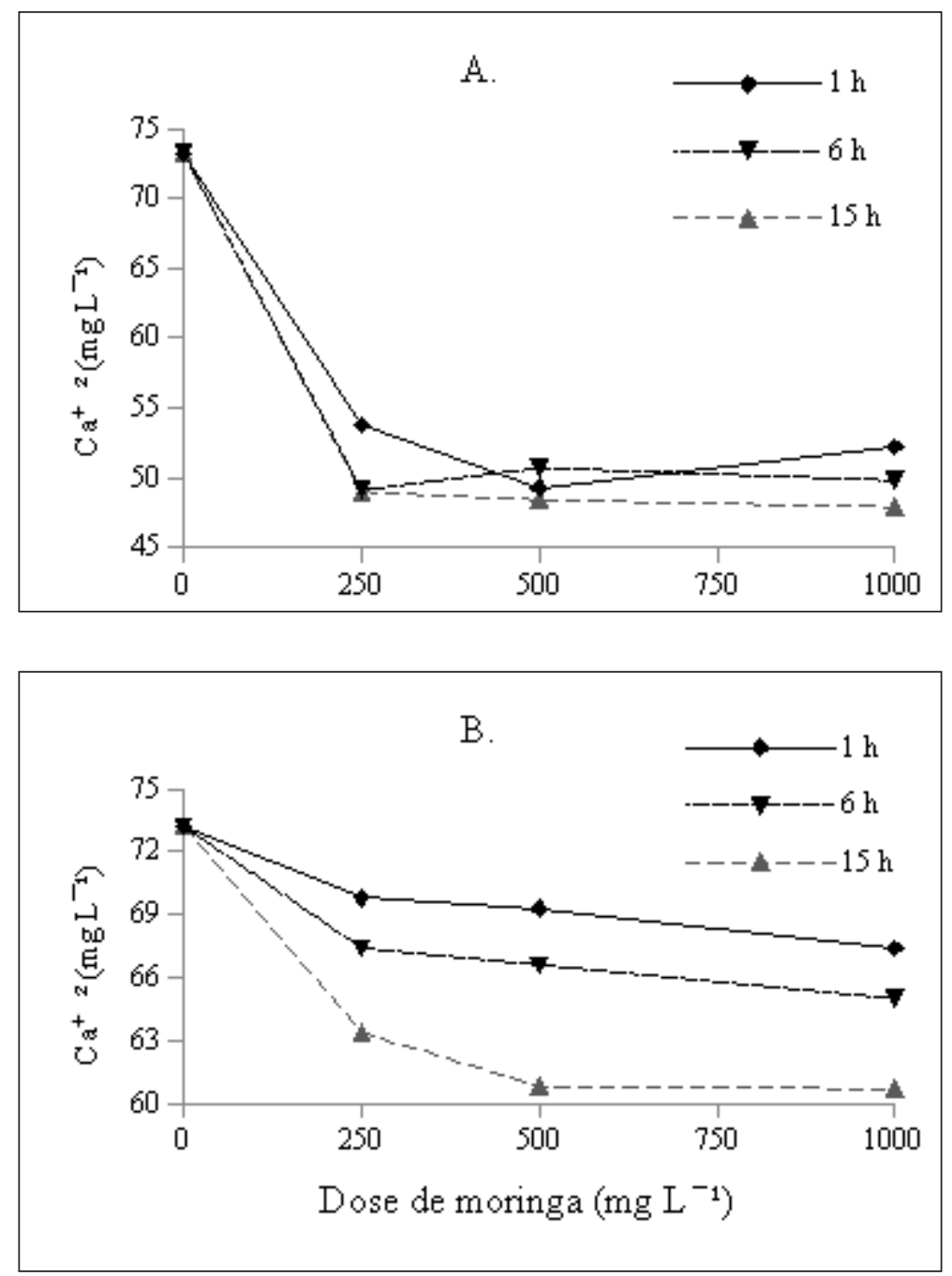

Fonte: Muniz, G. L. et al. (2018)

A remoção do magnésio mostrou-se diferente da remoção do cálcio e da dureza total, ou seja, não foi diretamente proporcional ao tempo de sedimentação e à dosagem de moringa (Figura 2). A concentração inicial de magnésio era $12,9 \mathrm{mg} \mathrm{L} \mathrm{L}^{-1}$, a aplicação das sementes sem cascas, Figura 2A, resultou em oscilação na concentração do íon nas amostras quando se utilizou o tempo de $1 \mathrm{~h}$ de sedimentação. 


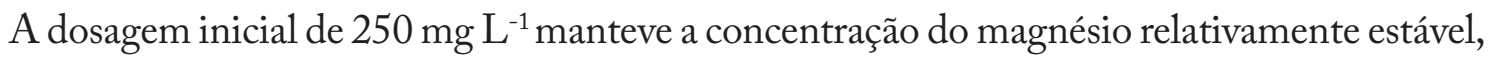
não sendo suficiente para sua remoção, já a dosagem de $500 \mathrm{mg} \mathrm{L}^{-1}$ proporcionou aumento na concentração deste íon. Aumentando-se ainda mais a dosagem para $1000 \mathrm{mg} \mathrm{L} \mathrm{L}^{-1}$, a concentração do magnésio diminuiu em relação à sua concentração inicial. Comportamento semelhante foi observado quando se utilizou sementes com cascas com 15 h de sedimentação.

\section{Figura 2 - Concentração residual de $\mathrm{Mg}^{+2}$ na água em função dos tempos de sedimentação e das dosagens de sementes de moringa sem casca (A) e com casca (B)}
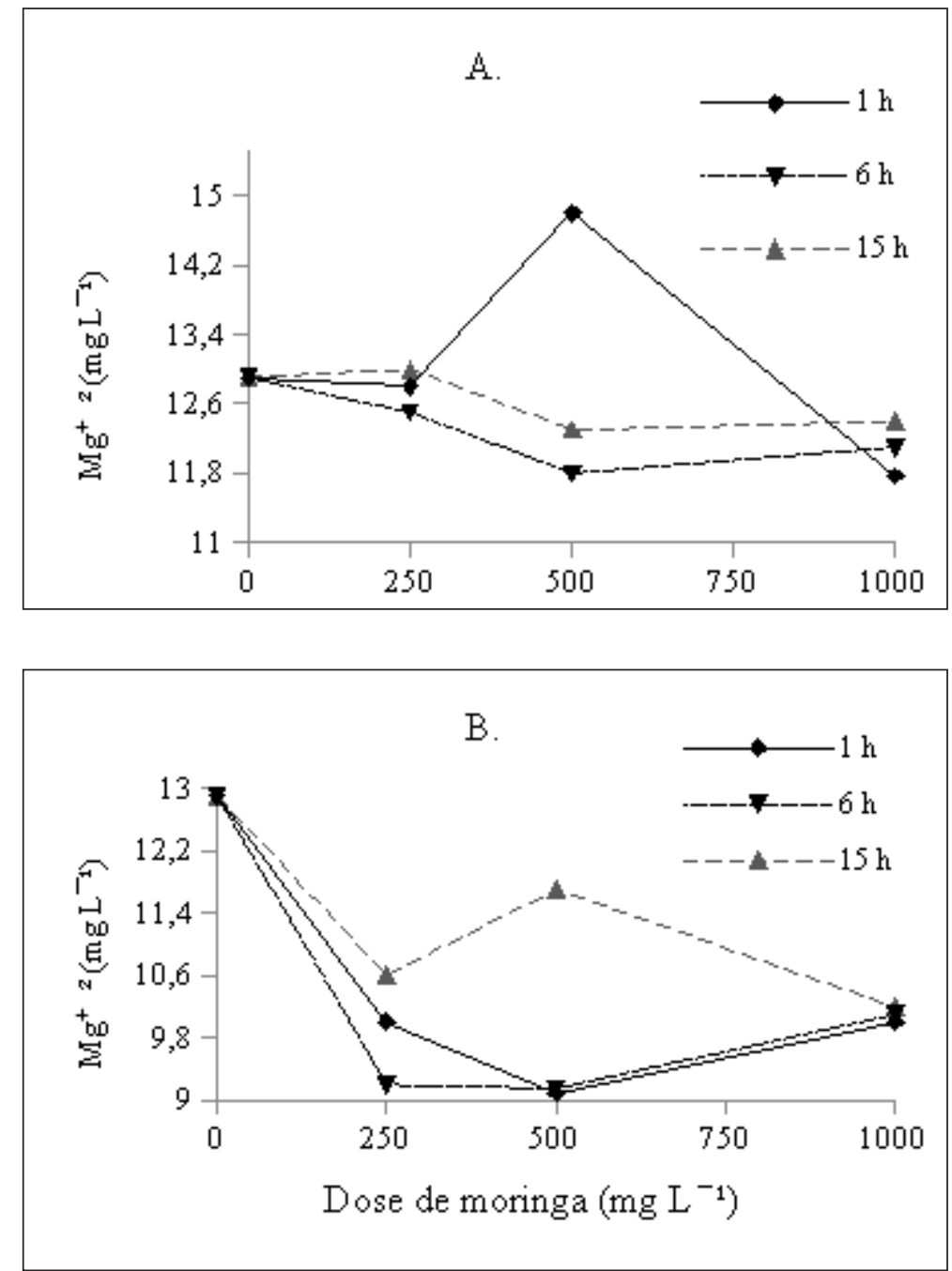

Fonte: Muniz, G. L. et al. (2018)

Muyibi e Evison (1995) utilizaram sementes de moringa sem cascas no abrandamento de água de poços subterrâneos, com dureza inicial de $495 \mathrm{mg} \mathrm{L}-1$ em $\mathrm{CaCO}_{3}$, e o tempo de $1 \mathrm{~h}$ de sedimentação e observaram redução de 40,5 e 80,0 $\mathrm{mg} \mathrm{L}^{-1}$ de cálcio nas amostras, aplicando 500 e $1000 \mathrm{mg} \mathrm{L}^{-1}$ de moringa, respectivamente. Ainda de acordo com esses mesmos autores, a dureza restante é devida, principalmente, ao magnésio, uma vez que os íons cálcio são adsorvidos mais rapidamente que os íons magnésio, o que corrobora com os resultados encontrados neste trabalho.

$\mathrm{A}$ adição de sementes de moringa à água não alterou significativamente seu $\mathrm{pH}$, como é mostrado na Figura 3. Houve oscilação do mesmo de 7,55 a 8,27, onde o valor máximo de pH foi observado nos tratamentos com $250 \mathrm{mg} \mathrm{L}^{-1}$ de moringa com $15 \mathrm{~h}$ de sedimentação, utilizando 
as sementes sem a casca. Essa variação do $\mathrm{pH}$ contribui para a precipitação de carbonato pois é suficiente para aumentar o índice de saturação da água.

\section{Figura 3 - Variação do pH da água em função dos tempos de sedimentação e das dosagens de sementes de moringa sem casca (A) e com casca (B)}
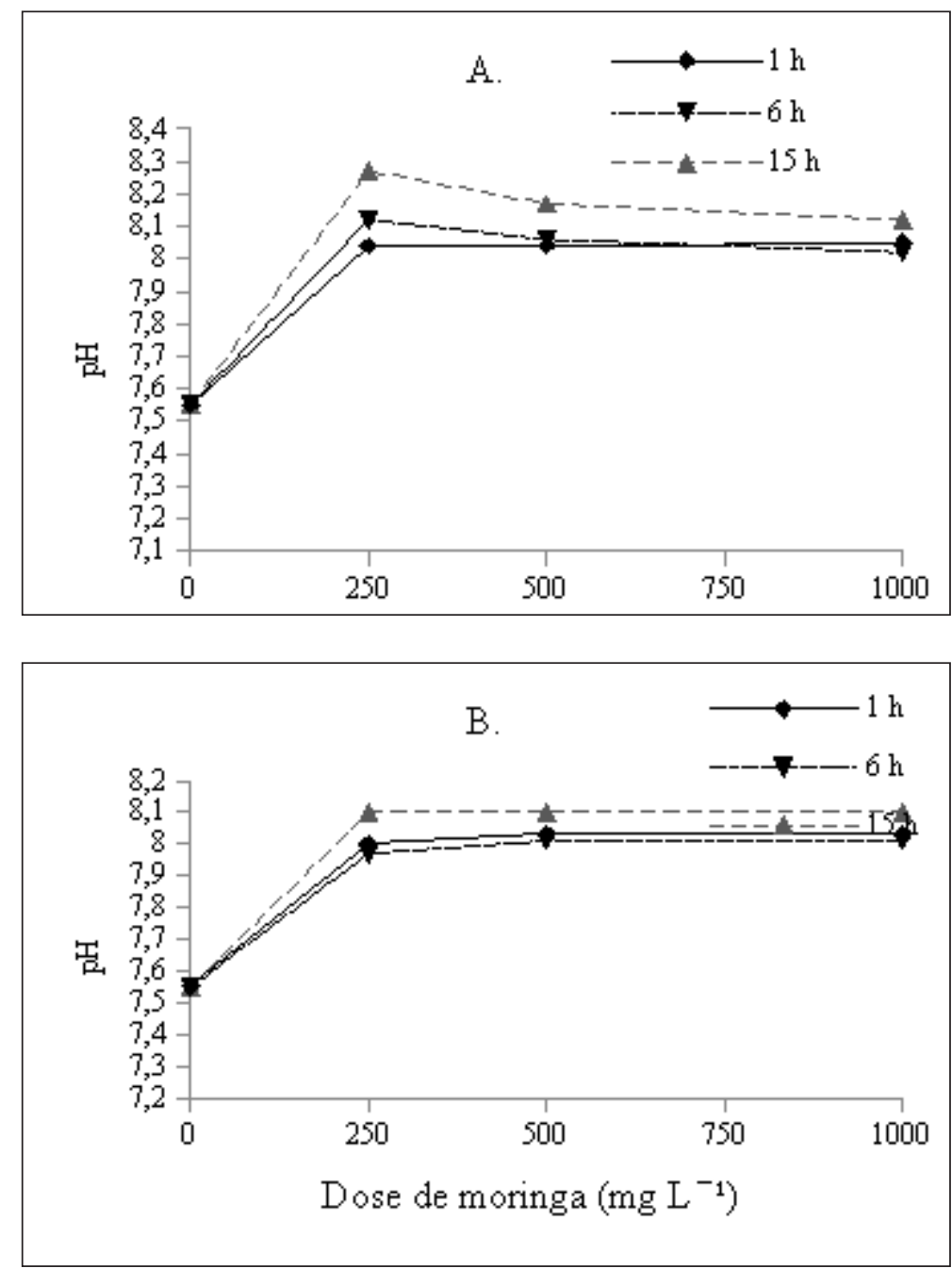

Fonte: Muniz, G. L. et al. (2018)

Em conformidade com este estudo, Oliveira et al. (2011) estudaram a ação coagulante das sementes de moringa em amostras de água natural e observaram oscilação do $\mathrm{pH}$ da água, que variou de 8,09 a 8,15, variação ocorrida, de acordo com estes autores, em função da concentração de moringa. Muyibi e Evison (1995) avaliaram o pH de amostras de água de poços subterrâneos tratada com moringa e observaram que o $\mathrm{pH}$ se mantém, relativamente, constante em 7,2 $\pm 1 \mathrm{a}$ partir de um $\mathrm{pH}$ inicial de 7,1 e 7,2, respectivamente.

Em estudo relacionado a este, Muyibi (1993) observou que o $\mathrm{pH}$ não tem efeito significativo na remoção da dureza utilizando sementes de moringa. Sendo assim, a independência do pH observado na redução da dureza utilizando sementes de moringa dispensa o uso de produtos químicos utilizados para o ajuste do $\mathrm{pH}$ no tratamento químico convencional.

Em relação à alcalinidade, como pode ser observado na Figura 4, à medida que se aumenta o tempo de sedimentação e a dosagem de semente, a alcalinidade da água reduz, fato que foi 
observado em todos os tratamentos e para ambas as sementes utilizadas, sendo que, o tempo de sedimentação de $15 \mathrm{~h}$ com a dosagem de $1000 \mathrm{mg} \mathrm{L}^{-1}$ de moringa proporcionaram maior redução na alcalinidade, de 250 para $211,7 \mathrm{mg} \mathrm{L}^{-1} \mathrm{em} \mathrm{CaCO}_{3}$. A redução na alcalinidade já era esperada pois, para águas com $\mathrm{pH}$ entre 6,5 e 8,3 a alcalinidade é devida ao bicarbonato $\left(\mathrm{HCO}_{3}{ }^{-}\right)$, que não precipita.

\section{Figura 4 - Variação da alcalinidade da água em função dos tempos de sedimentação e das dosagens de sementes de moringa sem casca (A) e com casca (B)}
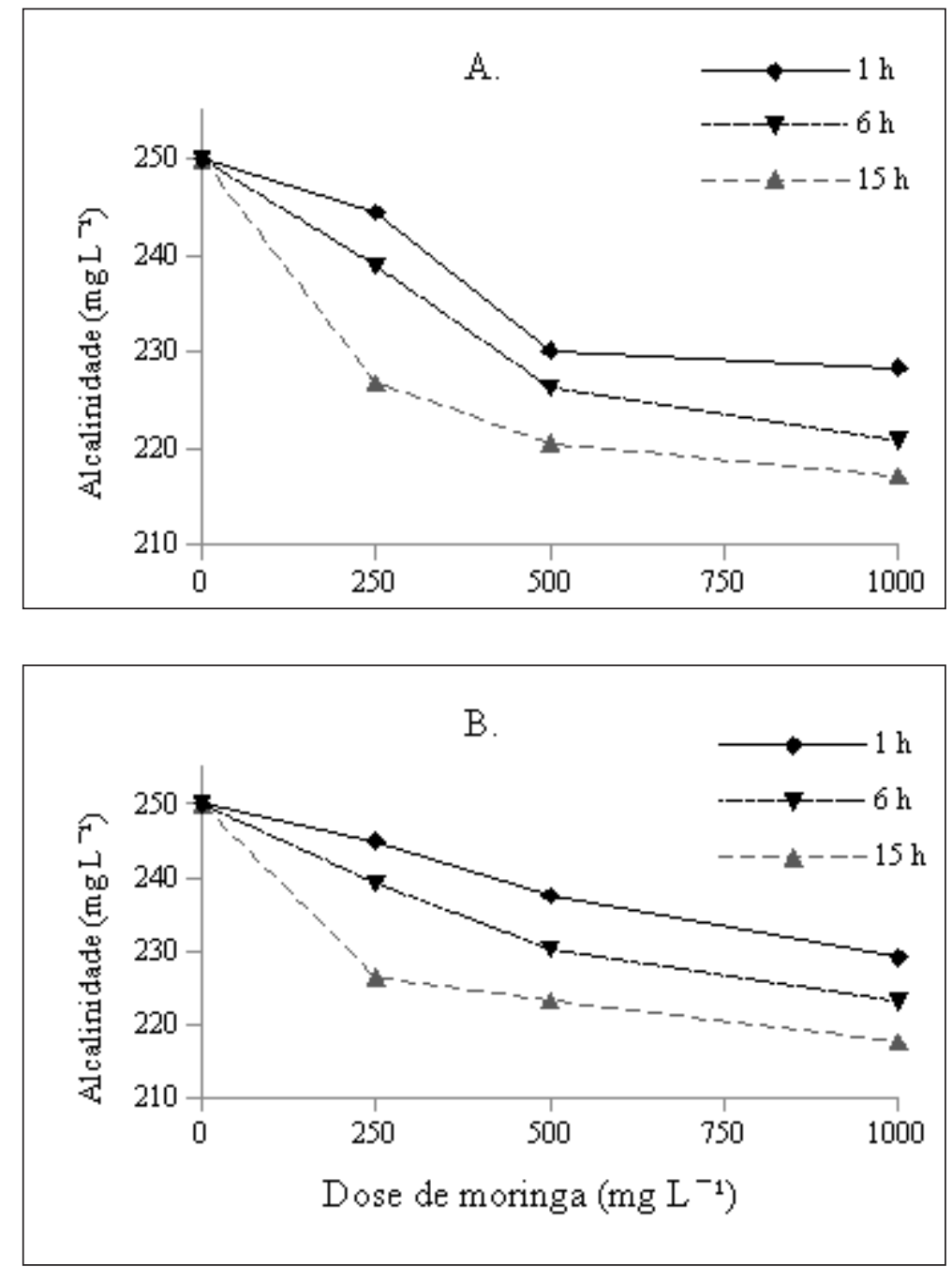

Fonte: Muniz, G. L. et al. (2018)

Muyibi e Evison (1995) aplicaram sementes de moringa para remover a dureza de águas subterrâneas e observaram redução da alcalinidade de 324 para $218 \mathrm{mg} \mathrm{L}^{-1} \mathrm{em} \mathrm{CaCO}_{3}$, utilizando $2100 \mathrm{mg} \mathrm{L}^{-1}$ de sementes de moringa. A redução da alcalinidade observada pelos autores corrobora com os resultados encontrados neste trabalho. De acordo com Mangale et al. (2012), a diminuição da alcalinidade e do $\mathrm{pH}$ das amostras de água relaciona-se à precipitação dos íons causadores da dureza com o extrato de moringa, formando produtos insolúveis. 
Conforme Muyibi e Okuofu (1996), o abrandamento de água com Moringa oleifera é vantajoso por causar uma baixa redução na alcalinidade, que é obrigada a fornecer a capacidade tampão necessária para atingir os objetivos dos tratamentos necessários, tornando assim, vantajoso o uso de suas sementes para abrandamento de água.

\section{Conclusões}

As sementes de moringa utilizadas sem a casca são mais eficientes do que das sementes utilizadas com a casca no abrandamento de água. Assim, recomenda-se o descascamento das sementes quando utilizadas para esta finalidade.

O coagulante extraído da semente de moringa é eficiente no abrandamento de água. Há dependência entre a dosagem do coagulante, o tipo de semente e o tempo de sedimentação no abrandamento de água, sendo que, a dosagem de $1000 \mathrm{mg} \mathrm{L}^{-1}$ e o tempo de sedimentação de 15 $\mathrm{h}$ promovem maior redução da dureza utilizando sementes de moringa sem as cascas.

$\mathrm{O} \mathrm{pH}$ e a alcalinidade da água, quando tratada com sementes de moringa, não variam significativamente, o que não requer produtos adicionais no tratamento convencional para ajustes dos mesmos após o tratamento.

\section{Referências}

AMERICAN PUBLIC HEALTH ASSOCIATION - APHA; AMERICAN WATER WORKS ASSOCIATION - AWWA; WATER ENVIRONMENT FEDERATION - WEF. Standard methods for the examination of water and wastewater. 21. ed. Washington: APHA/AWWA/WEF. 2005.1268p.

ANDREASEN, P., STUBSGAARD, A.E., Reduktion af Miljøbelastningen fra Tøjvask e Effekten af Blødgøring af Brugsvand før Vask, Arbejdsrapport fra Miljøstyrelsen Nr. 37 (Report. Eng.: Reduction of Environmental Impact from Laundry e The effect of Softening of Water Before Washing). Danish EPA. 2002.

BEZERRA, A.M.E.; MOMENTÉ, V.G.; MEDEIROS FILHO, S. Germinação de sementes e desenvolvimento de plântulas de moringa (Moringa oleifera Lam.) em função do peso da semente e do tipo de substrato. Horticultura Brasileira, Vitoria da Conquista, v.22, n.2, p.295-299, 2004.

BRASIL. Ministério da Saúde. Secretaria de Vigilância Sanitária. Portaria nº 2914 de 12 de dezembro de 2011. Dispõe sobre os procedimentos de controle e de vigilância da qualidade da água para o consumo humano e seu padrão de potabilidade. Diário Oficial da União, Brasília, 2011. Disponível em: <http://site.sabesp.com.br/site/uploads/ file/asabesp_doctos/PortariaMS291412122011.pdf> Acesso em: 21 mar. 2018.

BRASTAD, K.S.; HE, Z. Water softening using microbial desalination cell technology. Desalination, v.309, p.32-37, 2013. 
BRUGGEN, B.D.; VANDECASTEELE, C. Removal of pollutants from surface water and groundwater by nanofiltration: overview of possible applications in the drinking water industry. Environmental Pollution, v.122, n.3, p.435-445, 2003.

CORDEIRO, M.M.; GADELHA, C.L.M.; BOMFIM, E.O.; SILVA, T.C. Variações da Dureza da Água Captada de Poços do Aquífero Beberibe na Cidade de João PessoaPB. Revista Brasileira de Recursos Hídricos, Porto Alegre, v.17, n.4, p.239-247, 2012.

ČUDA, P.; POSPÍSIL, P.; TENGLEROVÁ, J. Reverse osmosis in water treatment for boilers. Desalination, v.198, n.1-3, p.41-46, 2006.

DUARTE, F.V. Influência da aplicação de gás carbônico na redução de precipitação de carbonatos em sistema de irrigação localizada. 2010. 123f. Tese (Doutorado em Saneamento Meio Ambiente e Recursos Hídricos) - Universidade Federal de Minas Gerais, Belo Horizonte, 2010.

FERREIRA, D. F. Sistema de análise de variância de dados balanceados SISVAR: pacote computacional. Lavras: UFLA/ DEX, 2000.

GALLÃO, M.I.; DAMASCENO, L.F.; BRITO, E.S. Avaliação química e estrutural da semente de moringa. Revista Ciência Agronômica, Fortaleza, v.37, n.1, p.106-109, 2006.

GASSENSCHMIDT, U.;JANY, K.D.; TAUSCHER, B.; NIEBERGALL, H. Isolation and characterization of a flocculating protein from Moringa oleifera Lam. Biochimica et Biophysica Acta, v.1243, p.477-481, 1995.

GHIZELLAOUI, S.; TAHA, S.; DORANGE, G.; CHIBANI, A.; GABON, J. Softening of Hamma drinking water by nanofiltration and by limein the presence of heavy metals, Desalination, v.171, p.133-138, 2005.

KATAYON, S.; NOOR, M.J.M.M.; ASMA, M.; GHANI, L.A.A.; THAMER, A.M.; AZNI, I.; AHMAD, J.; KHOR, B.C.; SULEYMAN, A.M. Effects of storage conditions of Moringa oleifera seeds on its performance in coagulation. Bioresource Technology, v.97, p.1455-1460, 2006.

MANGALE S.M.; CHONDE, S.G.; RAUT, P.D. Use of Moringa oleifera (drumstick) seed as natural absorbent and an antimicrobial agent for ground water treatment. Research Journal of Recent Sciences, v.1, n.3, p.31-40, 2012.

MUNIZ, G.L.; DUARTE, F.V.; OLIVEIRA, S.B. Uso de sementes de Moringa oleifera na remoção da turbidez de água para abastecimento. Revista Ambiente \& Água, Taubaté, v.10, n.2, p.454-463, 2015.

MUYBI, S.A.; EVISON, L. Moringa oleifera seeds for softening hardwater. Water Research, Londres, v.29, n.4, p.1099-1105, 1995. 
MUYIBI, S. A. The use of Moringa oleifera seeds in water treatment. Unpublished progress report of research. Univ. of Newcastle upon Tyne. 1993.

MUYIBI, S.A.; OKUOFU,C.A. Coagulation of low turbidity surface waters with Moringa oleifera seeds. International Journal of Environmental Studies, v.48, p.263-273, 1995.

MUYIBI, S.A.; OKUOFU, C.A. Softening hard well waters with Moringa oleifera seed extracts. International Journal of Environmental Studies, v.50, p.247-257, 1996.

NDABIGENGESERE, A.; NARASIAH, K.S. Quality of water treated by coagulation using Moringa oleifera seeds. Water Research, Londres, v.32, n.3, p.781-791, 1998.

NDABIGENGESERE, A.; NARASIAH, K.S.; TALBOT, B.G. Active agents and mechanism of coagulation of turbid waters using Moringa oleifera. Water Research, Londres, v.29, n.2, p.703-710, 1995.

OKUDA, T.; BAES, A.U.; NISHIJIMA, W.; OKADA, M. Isolation and characterization of coagulant extracted from Moringa oleifera seed by salt solution. Water Research, Londres, v.35, n.2, p. 405-410, 2001.

OUYANG, L.; MALAISAMY, R.; BRUENING, M.L. Multilayer polyelectrolyte films as nanofiltration membranes for separating monovalent and divalent cations, Journal of Membrane Science, v.310, p.76-84, 2008.

PATERNIANI,J.E.S.; MANTOVANI,M.C.; SANT'ANNA, M.R.Uso de sementes de Moringa oleifera para tratamento de águas superficiais. Revista Brasileira de Engenharia Agrícola e Ambiental, Campina Grande, v.13, n.6, p.765-771, 2009.

PATERNIANI,J.E.S.; RIBEIRO, T.A.P.; MANTOVANI,M.C.; SANT'ANNA,M.R. Water treatment by sedimentation and slow fabric filtration using Moringa oleifera seeds. African Journal of Agricultural Research, v.5, n.11, p.1256-1263, 2010.

PITTS, D.J.; HAMAN, D.Z.; SMAJSTLA, A.G. Causes and prevention of emitter plugging in microirrigation systems. Gainsville: University of Florida, 1990.

SEO, S.;JEON, H.; LEE,J. K.; KIM, G.H.; PARK, D.; NOJIMA, H.; LEE, J.; MOON, $\mathrm{S}$. Investigation on removal of hardness ions by capacitive deionization (CDI) for water softening applications. Water Research, v.44, n.7, p.2267-2275, 2010.

SILVA, G.F.; SANTOS, W.R.; MATOS, D.B.; OLIVEIRA, B.M.; SANTANA, T.M.; SANTANA, M.M. Estudo do tratamento e clarificação de água com torta de sementes de Moringa oleifera Lam. Revista Brasileira de Produtos Agroindustriais, Campina Grande, v.13, n.3, p.295-299, 2011. 
SOUZA, M.C.F.B.; OLIVEIRA, S. C.; PAIXÃO, M.M.O.M.; HAUSSMANN, M. G. Aspectos hidrodinâmicos e qualidade das águas subterrâneas do Aquífero Bambuí no Norte de Minas Gerais. Revista Brasileira de Recursos Hídricos, v.19, n.1, p.119-129, 2014.

TOFIGHY, M.A.; MOHAMMADI, T. Permanent hard water softening using carbon nanotube sheets. Desalination, v.268, p.208-213, 2011. 